\title{
RESISTÊNCIA DEMOCRÁTICA: A QUESTÃO RACIAL E A CONSTITUIÇÃO FEDERAL DE 1988
}

\author{
Nilma Lino Gomes ${ }^{1}$ (1) \\ Tatiane Cosentino Rodrigues ${ }^{2}$ (D)
}

\begin{abstract}
RESUMO: Numa abordagem retrospectiva, este artigo objetivou resgatar as discussóes sobre a temática étnico-racial no contexto da Assembleia Nacional Constituinte, responsável pela construção da Constituição Federal de 1988, considerada a "constituiçấo cidadâ". No marco dos seus 30 anos, é importante reconhecer na Constituição de 1988 tanto os limites do alcance político de seu textono tratamento da questáo racial, quanto os avanços que dela derivariam para a luta antirracista — avanços, sobretudo, ligados à implementaçáo de suas leis complementares. $\mathrm{O}$ artigo abordaas ambiguidades do texto constitucional no campo da educação e aponta os desdobramentos relevantes na luta por igualdade racial e por açóes afirmativas.
\end{abstract}

Palavras-chave: Relaçóes étnico-raciais. Constituição Federal. Educação. Movimento Negro.

\section{DEMOCRATIC RESISTANCE: THE RACIAL QUESTION AND THE 1988 FEDERAL Constitution}

\begin{abstract}
In a retrospective approach, this article aimed at reviewing the discussions on ethno-racial issues in the context of the National Constituent Assembly, responsible for the development of the Federal Constitution of 1988, considered the "citizen constitution". In the context of its 30 years, it is important to recognize in this Constitution both the limits of the political cope of its text in the treatment of the racial issue and the advances that would derive from it in the anti-racist struggle - advances mainly related to the implementation of its complementary laws. The article will address the ambiguities of the constitutional text in the field of education, and will point out the relevant developments in the struggle for racial equality and affirmative action.
\end{abstract}

Keywords: Ethnic-racial relations. Federal Constitution. Education. Black Movement.

\footnotetext{
${ }^{1}$ Universidade Federal de Minas Gerais, Faculdade de Educação - Belo Horizonte (MG), Brasil. E-mail: nilmagomes@uol.com.br ${ }^{2}$ Universidade Federal de São Carlos, Centro de Educação e Ciências Humanas, Programa de Pós-Graduação em Educação - São Carlos (SP), Brasil. E-mail: tatiane.rodrigues@gmail.com DOI: 10.1590/ES0101-73302018200256
} 


\section{RÉSISTANCE DÉMOCRATIQUE : LA QUESTION RACIALE ET LA CONSTITUTION FÉDÉRALE DE 1988}

$R E S U M E$ : Dans une approche rétrospective, cet article vise à reprendre les discussions sur les questions ethnique-raciales au contexte de l'Assemblée Nationale Constituante, responsable pour élaborer la Constitution Fédérale de 1988, considérée comme la " constitution citoyenne». Au cadre de ses 30 ans, il est important de reconnaître dans La Constitution de 1988 les limites politiques en traitant la question raciale tant quant les avances de la lutte antiracisme -liés principalement à La mise en œuvre de ses lois complémentaires. On oborde aussi les ambiguïtés du texte constitutionnel au domaine de l'éducation et souligneles conséquences pertinents pour lalutte pour l'égalité raciale et actions affirmatives.

Mots-clés : Relations ethniques-raciales. Constitution fédérale. Éducation. Mouvement Noir.

\section{Introdução}

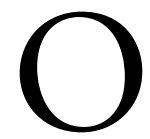

processo de democratização da sociedade brasileira é composto de uma série de coletivos, movimentos, sujeitos sociais e grupos culturais com atuação importante na garantia de direitos. No entanto, a literatura sociológica, política e educacional brasileira, ao discutir esses caminhos e lutas políticas, tende a dar mais visibilidade à participação de determinados grupos em detrimento de outros. Em alguns casos, é mais do que uma visibilidade parcial. É uma ausência. Concordando com os estudos realizados por Santos (2004), é possível problematizar essa ausência e entendê-la como intencionalou, nos dizeres do autor, como ativamente produzida.

Para superar esse processo de ausências epistemológicas no campo da produção de conhecimento e, no caso específico da reflexão aqui realizada, no campo da política educacional, será importante empreender um procedimento político-epistemológico desenvolvido por Santos (2004) e por ele denominado como "sociologia das ausências e das emergências".

A aplicação desse procedimento implica compreender como nos contextos das relaçóes de poder, do colonialismo, do capitalismo, do racismo e tantas outras formas de dominação, determinados sujeitos, histórias, participaçóes políticas, conhecimentos e conquistas foram invisibilizados no campo epistemológico e político e, mais do que isso, muitos se tornaram ausentes.

Para superar essa situação é necessário reconhecer a existência desses sujeitos e processos, bem como dos conhecimentos por eles produzidos, os quais 
são tão válidos quanto o conhecimento científico. Além disso, é necessário fazer emergir as experiências sociais, culturais e políticas produzidas por esses sujeitos e construídas nesses processos, para compreendê-las e traduzi-las culturalmente e, assim, entender a constelação de saberes que é produzida nas mais diversas experiências sociais no mundo, as quais também são fonte de conhecimento.

É nessa perspectiva que compreendemos a questão racial no contexto da Assembleia Nacional Constituinte (ANC), responsável pela construção da Constituição Federal de 1988 (CF/88), considerada a "constituição cidadâ".

Entretanto, de quais cidadãos falamos quando pensamos na constituição cidadã? No contexto das desigualdades sociorraciais, de gênero e econômicas, sabemos que determinados sujeitos sempre estiveram náo somente fora do direito à cidadania. A exclusão e a discriminação sobre eles impostas historicamente pelas relaçóes de poder os retiravam, também, do imaginário cidadão. Eles são os negros, as mulheres, os quilombolas, os indígenas, as pessoas do campo, as pessoas com deficiência, a população LGBT. Foram, no entanto, os próprios sujeitos excluídos da perspectiva dos conservadores e do campo da direita, bem como de vários debates progressistas sobre cidadania, que primavam apenas pelo olhar da classe social e se impuseram à sociedade, ao Estado eà ciência, que se fizeram ser reconhecidos como cidadãos de direitos. Porém, não de um direito abstrato, mas de um direito que os reconheça na sua diferença.

É fato que os direitos garantidos na $\mathrm{CF} / 88$ sinalizaram e ajudaram a construir a redemocratização brasileira após a queda da ditadura militar. Construímos uma democracia ainda frágil, mas fruto de intensas lutas sociais e da qual não abrimos mão. Esse processo de redemocratização não foi protagonizado apenas pela tensão entre os partidos políticos, os sindicatos, os grupos religiosos e os capitalistas. Há um sujeito político que atuou intensamente na luta contra a ditatura e pela retomada democrática: os movimentos sociais. Vivendo na clandestinidade no contexto das ditaduras impostas ao Brasil, os ativistas e as ativistas de diversas organizaçóes foram protagonistas na luta contra o racismo, sofreram a opressão dos governos autoritários e do militarismo, viveram a violência e a dominação. Contudo, nem sempre as suas histórias, bem como as suas lutas antirracistas e democráticas, são contadas e reconhecidas.

As negras e os negros que lutaram e lutam contra o racismo e o movimento negro organizado são alguns desses sujeitos políticos atuantes socialmente; porém, invisibilizados política e epistemologicamente.

Negras e negros organizados politicamente no Brasil sempre reconheceram que a luta contra o racismo não poderia acontecer separada da luta pela democracia. Por isso, no processo de retomada democrática dos anos de 1980 do século XX, o movimento negro foi um protagonista importante na construção da $\mathrm{CF} / 88$. Os poucos parlamentares negros eleitos foram personagens fundamentais na construção de alianças políticas para que demandas históricas pleiteadas pela população negra após a abolição e o advento da República se tornassem direitos e induzissem políticas públicas. 
O protagonismo, as demandas, as negociaçóes, os avanços e os limites da luta política e constitucional pelos direitos da população negra realizados pelo movimento negro ainda têm sido escamoteados pela teoria educacional e pelos estudos da política educacional. Trazê-los à cena, dar-lhes visibilidade, fazê-los presentes é ainda um esforço teórico necessário, que realizamos no presente artigo ao refletirmos sobre os 30 anos da CF/88.

\section{O significado da Constituição Federal de 1988}

Na história recente brasileira, a década de 1980 foi marcada por importantes transformaçóes políticas e institucionais. Sob a perspectiva da sociedade civil organizada, os debates acerca da garantia dos direitos sociais e individuais se consolidariam como marca da redemocratização do país. Esses debates viriam a atingir seu clímax na elaboração da nova CF/88.

No que concerne ao movimento negro, a CF/88 refletiria a densidade de sua atuação política. Conquistas como a possibilidade de reconhecimento de terras quilombolas e a posterior criminalização do racismo são indicadores importantes da atuação desse movimento. Nos tópicos referentes à educação, contudo, as reivindicaçóes do movimento negro não foram acolhidas do mesmo modo. $\mathrm{Na}$ ocasião, o movimento apontava a necessidade de que o sistema educacional reforçasse as implicaçóes da discriminação racial e do racismo na contenção da mobilidade social da população negra. A ênfase sobre essa realidade acabara por ser demasiadamente prejudicada por causa da não incorporação da noção de raça nas premissas que fizeram parte da discussão dos direitos e da organização do sistema educacional nacional.

O movimento negro e seus interlocutores políticos se organizariam para influir no conteúdo das duas principais legislaçóes que iriam orientaras políticas educacionais - notadamente a CF/88 e a Lei de Diretrizes e Bases da Educação Nacional (LDB) no 9.394/1996. O objetivo passaria a ser inserir a discussão da temática racial nesse processo a fim de que as políticas públicas em educação reconhecessem e valorizassem as características multiculturais da sociedade brasileira, especialmenteas referentes à população negra. Do ponto de vista do conteúdo, as críticas do movimento poriam sob suspensão um dos principais fundamentos da matriz educacional, qual seja, sua orientação eurocêntrica e homogeneizadora, viabilizada por um discurso de democracia racial.

\section{A recepção do tema na Constituinte}

Com o propósito de pautar a questão racial na ANC de 1987-1988, o movimento negro organizara encontros municipais e estaduais com o objetivo específico de discutir estratégias de participação no processo constituinte. 
Entre esses, destaca-se o Primeiro Encontro Estadual, chamado "O negro e a constituinte", realizado em julho de 1985 na Assembleia Legislativa de Minas Gerais. A partir desse encontro, foi produzido um documento que seria entregue, em audiência pública no dia 3 de dezembro de 1986, ao Presidente da República, José Sarney, e, mais tarde, ao presidente da ANC, Deputado Ulisses Guimarães.

Essas ações organizadas pelo movimento negro prolongaram-se por todo o ano de 1986, culminando com a realização, em Brasília, da Convenção Nacional "O Negro e a Constituinte", da qual se originou um documento sintetizando os Encontros Regionais ocorridos em várias Unidades da Federação.

A ideia de que a questão racial deveria ser tratada suscitou reaçóes. Carlos Alberto Caó ${ }^{1}$ (Partido Democrático Trabalhista - PDT), que, como deputado constituinte, regulamentou o trecho da CF que torna inafiançável ou imprescritível o crime de racismo, explicou, em entrevista concedida ${ }^{2}$, esse momento:

$\mathrm{O}$ argumento era de que não deveria ser dado tratamento específico à questáo, chegara-se a afirmar que a luta contra o racismo, como apareceu depois na Constituinte, tinha aspectos extremamente perigosos porque poderia provocar uma certa cisão da classe operária, isso do lado dos aliados que resistiam ao regime. Do lado do regime, era a permanente construção do falso mito da democracia racial.

Esse debate e a luta para que o bloco de forças contra o regime considerasse a questão racial brasileira como uma questão de suma importância foi conduzido por uma minoria de determinados líderes negros, enfrentando preconceitos, constrangimentos, e até as vésperas da Constituinte ainda persistia essa ambiguidade, entre democratas com sua visão marxista que não davam à questão racial brasileira o status teórico e político como questão central na transformação democrática do país, mas nós chegamos na Constituinte com um significativo avanço, esse tema tem que ser tratado, abordado.

Conforme aponta o depoimento de Caó, a persistência da uma posição que propunha o apagamento da questão racial no processo constituinte não pode ser atribuída apenas aos setores conservadores. Por motivos distintos, setores progressistas também repercutiam a visão de que o problema racial fora equacionado, ou que poderia ser resolvido com a simples integração do negro na sociedade de classes. Ao menos nesse aspecto, tratavam-se de dois grupos acríticos quanto à visão freireana (inspirada no tipo de interpretação do Brasil realizada pelo sociólogo Gilberto Freyre), como bem se observará nas dificuldades encontradas pelo movimento negro durante a elaboração da CF/88. 


\section{A Assembleia Nacional Constituinte}

Nos trabalhos da ANC, a determinação, viaregimento interno, de que a temática racial seria abordada agradou as organizaçóes do movimento negro, que acompanhavam esse processo com expectativa, a despeito da percepçáo de que o espaço destinado a essa discussão desde cedo se mostrara bastante limitado. Somava-se a isso a equivocada abordagem da questão racial, classificada como temática de minoria, uma interpretaçáo contrária à opiniáo dos militantes do movimento negro.

Do ponto de vista institucional, a organização da ANC restringiu a temática racial exclusivamente à "Subcomissão dos Negros, Populações Indígenas, Pessoas Deficientes e Minorias", que integrava a Comissão Temática "Da Ordem Social". Os trabalhos da subcomissáo se iniciaram com ressalvas do movimento negro à estrutura organizacional e decisória da Constituinte, visto que o espaço ao debate racial, sob tal formato, estaria preso à referida subcomissão. Outro aspecto crítico desse enquadramento institucional se baseia na amplitude de temáticas reunidas na mesma subcomissão, situação que acabara por restringir a discussão da questáo racial a dois encontros formais. Por fim, a dificuldade de instalação da subcomissão em razão da ausência de quórum refletiria mais um dos aspectos limitadores da estrutura decisória e a pouca importância atribuída ao tema na ANC. O Quadro 1 apresenta a agenda dessa subcomissão, ao mesmo tempo que expressa a abrangência de temas com especificidades distintas reunidos nesse mesmo espaço da ANC.

Apesar das dificuldades, foi no escopo dessa subcomissão que o movimento negro apresentou suas propostas e acompanhou o desenvolvimento dos trabalhos na ANC. Ainda que tenha sido um espaço limitado em tempo e amplitude, o trabalho da subcomissão resultou na aprovação de um anteprojeto que guardou maior proximidade com as propostas apresentadas pelo movimento negro.

\section{Quadro 1}

Cronograma de compromisso da Subcomissão dos Negros, População Indígena, Pessoas Deficientes e Minorias.

\begin{tabular}{|l|}
\hline 27/04 - Deficientes mentais, alcoólatras e deficientes auditivos \\
\hline 28/04 - Negros \\
\hline 29/04 - Populações indígenas/homossexuais \\
\hline 30/04 - Deficientes físicos/ostonizados/hansenianos/talassêmicos \\
\hline $04 / 05$ - Deficientes visuais/hemofílicos/negros \\
\hline $\begin{array}{l}\text { 05/05 - População indígena/presidiários (incluindo visita ao presídio do Papuda, em Brasília), } \\
\text { minorias raciais e religiosas }\end{array}$ \\
\hline 06/05 - Visita à aldeia Kaiapó, na reserva Gorotiré, no sul do Pará \\
\hline
\end{tabular}

Fonte: Rodrigues (2005). 
Para tanto, além da importante atuaçáo dos ativistas do movimento negro nessa subcomissão, também foi fundamental o papel desempenhado pelos interlocutores que, no cenário político, estavam mais próximos das decisóes e, de alguma forma, representavam os interesses da comunidade negra. Entre esses interlocutores estavam a senadora Benedita da Silva e os deputados federais Carlos Alberto Caó, Edmilson Valentim e Paulo Paim³.

Não foi possível identificar todas as entidades do movimento negro que estiveram presentes na subcomissão. As notas taquigráficas registram aquelas pessoas/representantes que fizeram uso do direito de voz durante as discussóes e, dessa forma, os nomes a seguir não dizem respeito ao todo. Foram registrados: Lélia Gonzáles, Helena Teodoro e Maria da Graça dos Santos, do Movimento Negro Unificado (MNU); Murilo Ferreira, da Fundação Afro-brasileira de Recife; Lígia Garcia Melo, do Centro de Estudos Afro-brasileiros; Orlando Costa, do Instituto Nacional Afro-brasileiro (INABRA); Januário Garcia, Mauro Pare, Professor Lauro Lima, Professor Paulo Roberto Moura, Natalino Cavalcanti de Melo e Raimundo Gonçalves dos Santos, do Núcleo Cultural de Girocan da Bahia; Lino de Almeida, do Conselho de Entidades Negras da Bahia; Marcília Campos Domingos, do Centro de Estudos Afro-Brasileiros (CEAB); B. de Paiva, do Teatro Experimental do Negro (TEN); Hugo Ferreira e Ricardo Dias, do Conselho da Comunidade Negra de São Paulo; e João do Pulo Carlos de Oliveira, Joel Rufino e Gilberto Gil.

É importante ressaltar que,entre1983 e 1987, Abdias do Nascimentose tornou o primeiro congressista, como deputado federal, a defender explicitamente no Congresso temas e direitos pertinentes à equidade étnico-racial.

As propostas e a participação do movimento negro foram marcadas pela denúncia do mito da democracia racial e de seu efeito desmobilizador na sociedade brasileira - no Quadro 2, é possível acompanhar as propostas encaminhadas por essa subcomissão à Comissão da Ordem Social. Esse efeito deveria ser corrigido por uma intervenção estatal na configuração das relaçóes raciais tanto com medidas que deveriam atuar nas consequências provocadas pela ausência de qualquer política voltada à integração da população ex-escravizada ao sistema produtivo, quanto medidas que possibilitassem aos negros a reconstrução da identidade racial que lhes fora historicamente negada por meio das conhecidas políticas de branqueamento (DÁVILA, 2006; STEPAN, 2005).

Para o movimento negro, essa situação poderia ser rompida ou remediada na $\mathrm{CF} / 88$ com as seguintes propostas principais:

- o reconhecimento, por parte do Estado, das comunidades negras remanescentes de quilombos e o título de propriedade definitiva de suas terras, o que se tratava do reconhecimento das especificidades culturais e históricas dessas comunidades, bem como da iniciativa de preservar e garantir o direito à terra; 
- a criminalização da prática do racismo, do preconceito racial e de qualquer discriminação atentatória aos direitos humanos;

- uma educação comprometida com o combate ao racismo e a todas as formas de discriminação, que valorize e respeite a diversidade, assegurando a obrigatoriedade do ensino de história das populações negras do Brasil.

Essas propostas foram permeadas pela denúncia da insuficiência do discurso de igualdade perante a lei em vigência desde a CF de 1934, apresentando, para a CF/88, a reivindicação por medidas compensatórias voltadas à implantação do princípio constitucional de isonomia a pessoas ou grupos vítimas de discriminação comprovada. No caso da educação, essas medidas garantiriam condições de acesso e permanência de crianças e jovens negros no sistema escolar, em especial no Ensino Superior.

\section{Quadro 2}

Anteprojeto elaborado pela Subcomissão dos Negros, Populações Indígenas, Pessoas Deficientes e Minorias.

\section{Artigos encaminhados à Comissáo da Ordem Social}

Negros

Art. $3^{\circ}$ - Constitui crime inafiançável subestimar, estereotipar ou degradar grupos étnicos, raciais ou de cor, ou pessoas pertencentes aos mesmos, por meio de palavras, imagens ou representaçóes, através de quaisquer meios de comunicaçáo.

Art. $4^{\mathrm{o}}$ - Não constitui privilégio a aplicação, pelo Poder Público, de medidas compensatórias visando à implementação do princípio constitucional de isonomia a pessoas ou grupos vítimas de discriminação comprovada.

Art. $5^{\circ}$ - A Educaçáo dará ênfase à igualdade dos sexos, à luta contra o racismo e todas as formas de discriminaçáo, afirmando as características multiculturais e pluriétnicas do povo brasileiro.

Art. $6^{\circ}-\mathrm{O}$ ensino de "História das Populaçóes Negras do Brasil" será obrigatório em todos os níveis da educaçấo brasileira, na forma que a lei dispuser.

Art. $7^{\circ}$ - Caberá ao Estado, dentro do sistema de admissão nos estabelecimentos de ensino público, desde a creche até o segundo grau, a adoção de uma açáo compensatória visando à integraçáo plena das crianças carentes, a adoção de auxílio suplementar para alimentaçáo, transporte e vestuário, caso a simples gratuidade de ensino não permita, comprovadamente, que venham a continuar seu aprendizado.

Art. $8^{\circ}$ - O Estado garantirá o título de propriedade definitiva das terras ocupadas pelas comunidades negras remanescentes de Quilombos.

Art. $9^{\circ}$ - Lei Ordinária disporá sobre a fixação de datas comemorativas de alta significação para os diferentes segmentos étnicos nacionais.

Art. $10^{\circ}$ - O País não manterá relações diplomáticas e não firmará tratados, acordos ou convênios com países que desrespeitem os direitos constantes da Declaração Universal dos Direitos do Homem, bem como não permitirá atividades de empresas desses países em seu território. 
A proposta de criminalizaçáo do preconceito racial foi considerada impossível de ser realizada. Conforme justificativa apresentada no anteprojeto, a impossibilidade de implementaçáo estaria em sua característica de pessoalidade, trazendo à tona a dimensão subjetiva do comportamento social. A não criminalizaçáo do preconceito seria compensada pela criminalizaçáo da discriminaçáo e pela "ação da educação que passa a cuidar desse assunto pela base, promovendo a correta interpretação da história das populaçooes" ${ }^{\text {. }}$. Dessa forma, o artigo passaria a ter a seguinte redação:

Art. $3^{\circ}$ - Constitui crime inafiançável subestimar, estereotipar ou degradar grupos étnicos, raciais ou de cor, ou pessoas pertencentes aos mesmos, por meio de palavras, imagens ou representaçóes, através de quaisquer meios de comunicação (BRASIL, 1987).

Embora a nova redação do artigo tenha retirado a criminalização do preconceito racial em razão de seu caráter subjetivo e da impossibilidade de puni-lo, a nova redação do artigo acabou reduzindo a definição de crimes raciais a condutas praticadas exclusivamente pelos meios de comunicação. Esse aspecto reducionista foi apontado na proposta de emenda 5 ao texto, apresentada pela deputada Anna Maria Rattes. A emenda, contudo, seria recusada.

Em relação à educação, o anteprojeto da subcomissão enfatizaria seu papel central e a escola como espaço para a valorização da diversidade e o combate ao racismo e a todas as demais formas de discriminação. A obrigatoriedade do ensino de "História das populaçóes negras do Brasil" inseria-se em um estratégico esforço de resgate e valorização da história e cultura afro-brasileira e africana, contribuindo, assim, para o respeito e o conhecimento dos processos históricos de resistência negra dos povos escravizados no Brasil.

O principal debate em torno da educação diria respeito ao currículo escolar. A rigor, a discussão versava sobre as formas de inclusãodo negro como sujeito na História do Brasil. Essa inclusão, somada ao ensino da História do negro na África, permitiria a composição de um conteúdo crítico em relação à ótica hegemônica e eurocentrada sobre a formação da sociedade brasileira. Daí a garantia, no texto constitucional, de que a história e a cultura do negro e do índio seriam tratadas nos três níveis do sistema educacional:

Art. $4^{\circ}$ - A educaçáo dará ênfase à igualdade dos sexos, à luta contra o racismo e todas as formas de discriminação, afirmando as características multiculturais e pluriétnicas do povo brasileiro.

Art. 5 - O ensino de "História das Populações Negras do Brasil" será obrigatório em todos os níveis da educação brasileira, na forma que a lei dispuser (BRASIL, 1987) ${ }^{6}$. 
As reduçôes e a descaracterização do anteprojeto, aprovado na subcomissão, iniciaram-se com o encaminhamento do projeto às comissões posteriores, em que o texto constitucional foi debatido e modificado.

Além da dispersão ${ }^{7}$ dos artigos sobre a questão racial e o racismo no texto da $\mathrm{CF} / 88$, alguns deles foram reduzidos ou omitidos. Este seria o caso do princípio de que não constitui privilégio a adoção de medidas compensatórias a grupos discriminados e, juntamente com isso, toda a discussão sobre ação afirmativa, que sequer chegou à comissão de sistematização.

$\mathrm{Na}$ sequência do debate sobre educação, as propostasdo anteprojeto, consolidado na Comissão Temática "Da Ordem Social”, terminariam por retirar a obrigatoriedade do "Ensino de História das Populaçôes Negras do Brasil", restando a indicação de reformulação do ensino de História do Brasil:

Art. 85 - O Poder Público reformulará, em todos os níveis, o ensino de história do Brasil, com o objetivo de contemplar com igualdade a contribuição das diferentes etnias para a formação multicultural e pluriétnica do povo brasileiro (BRASIL, 1987).

O processo de descaracterização e as mudanças sugeridas ao projeto podem ser acompanhados no Quadro 3, que sintetiza as propostas apresentadas pela Comissão da Ordem Social.

O documento final da Constituição, por sua vez, apenas sinalizaria a necessidade de que o currículo escolar refletisse a pluralidade racial brasileira, na medida em queas reivindicaçóes do movimento negro quanto à alteração curricular na educação foram consideradas muito específicas, devendo ser tratadas em leis ordinárias. Nesse sentido, foram retiradas do documento as propostas de obrigatoriedade do estudo da cultura e história da África nos currículos dos três níveis de ensino, além da proposta de reformulação dos currículos de História do Brasil. Ademais, a emenda ${ }^{8}$, apresentada pelo constituinte Geraldo Campos (Partido do Movimento Democrático Brasileiro PMDB), ainda caracterizaria a ênfase no ensino de História das populaçóes negras como atitude discriminatória.

De forma integral, no texto da CF/88, como mostra o Quadro 4, permaneceram as propostas sobre os quilombos e a criminalização do racismo. Ainda assim, essa última só fora aprovada por causa da mobilização do movimento negro e das intensas articulaçóes políticas realizadas, principalmente, por Carlos Alberto Caó na Comissão de Sistematização, onde, inicialmente, a proposta seria rejeitada por ser considerada uma ameaça à liberdade de expressão.

Para Carlos Alberto Caó, a criminalização do racismo seria a marca impressa pelo movimento negro na Constituição: 
Houve um esforço considerável de mobilização do movimento negro, depois de um tão longo período de reclusão. Mas nós nos apresentamos, com todas as debilidades, o que ajudou a concretizar o racismo como crime foi também o clima geral na sociedade brasileira contra o autoritarismo. Essa foi a marca que conseguimos imprimir. As resistências foram muitas às propostas de ação afirmativa, políticas compensatórias foram apresentadas e examinadas, mas tudo isso foi cortado, cortado?

\section{Os limites do antirracismo brasileiro}

Segundo Gomes (2001), na ordem jurídica interna brasileira, além dos dispositivos constitucionais genéricos que proíbem a discriminação racial e criminalizam certos comportamentos discriminatórios, nosso direito se singulariza pela estratégia de pretender extinguir a discriminação racial e os seus efeitos mediante leis de conteúdo criminal. $\mathrm{O}$ autor salienta a ineficiência de tais leis que, muitas vezes, são objeto de deboche por parte de alguns operadores do direito:

\section{Quadro 3}

Anteprojeto apresentado pela Comissão da Ordem Social.

Art. 65 - Todos, homens e mulheres, são iguais perante a lei, que punirá como crime inafiançável qualquer discriminação atentatória aos direitos humanos e ao aqui estabelecidos.

Parágrafo Único - são formas de discriminação, entre outras, subestimar, estereotipar ou degradar grupos étnicos, raciais ou de cor, ou pessoas a eles pertencentes, por palavras, imagens ou representaçóes, em qualquer meio de comunicação.

Art. 66 - Não constitui privilégio a aplicação, pelo Poder Público, de medidas compensatórias visando à implementação do princípio constitucional de isonomia a pessoas ou grupos vítimas de discriminação comprovada.

Art. 67 - A educação dará ênfase à igualdade dos sexos, afirmará as características multiculturais e pluriétnicas do povo brasileiro e condenará o racismo e todas as formas de discriminação.

Art. 68 - O Brasil não manterá relações diplomáticas nem firmará tratados, acordos ou pactos com países que adotem políticas oficiais de discriminação de cor, bem como não permitirá atividades de empresas desses países em seu território.

\section{Seçáo I - Das Disposiçóes Transitórias}

Art. 85 - O Poder Público reformulará, em todos os níveis, o ensino de história do Brasil, com o objetivo de contemplar com igualdade a contribuição das diferentes etnias para a formação multicultural e pluriétnica do povo brasileiro.

Parágrafo Único - A lei disporá sobre a fixação de datas comemorativas de alta significação para os diferentes segmentos étnicos nacionais.

Art. 86 - Fica declarada a propriedade definitiva das terras ocupadas pelas comunidades negras remanescentes dos quilombos, devendo o Estado emitir-lhes os títulos respectivos.

Fonte: Rodrigues (2005). 


\section{Quadro 4}

Questões que permaneceram na Constituição da República Federativa do Brasil.

\section{Constituiçáo da República Federativa do Brasil}

Título I - Dos Princípios Fundamentais

Art. $3^{\circ}$ - Constituem objetivos fundamentais da República Federativa

$[\ldots]$

IV - promover o bem de todos, sem preconceitos de origem, raça, sexo, cor, idade e quaisquer outras formas de discriminaçáo.

Título II - Dos Direitos e Garantias Fundamentais

Capítulo I - Dos Direitos e Deveres Individuais e Coletivos

XLII - A prática do racismo constitui crime inafiançável e imprescritível, sujeito à pena de reclusão, nos termos da lei;

Seção II - Da Cultura

Art. 215 - O Estado garantirá a todos o pleno exercício dos direitos culturais e acesso às fontes da cultura nacional, e apoiará e incentivará a valorização e a difusão das manifestaçôes culturais.

$\$ 1^{\circ} \mathrm{O}$ Estado protegerá as manifestaçóes das culturas populares, indígenas e afro-brasileiras, e das de outros grupos participantes do processo civilizatório nacional.

$\$ 2 \circ$ A lei disporá sobre a fixação de datas comemorativas de alta significação para os diferentes segmentos étnicos nacionais.

Art. 216 - Constituem patrimônio cultural brasileiro os bens de natureza material e imaterial, tomados individualmente ou em conjunto, portadores de referência à identidade, à ação, à memória dos diferentes grupos formadores da sociedade brasileira, nos quais se incluem:

$\$ 5^{\circ}$ Ficam tombados todos os documentos e os sítios detentores de reminiscências históricas dos antigos quilombos.

Título IX - Das Disposições Constitucionais Gerais

Art. $242-[\ldots]$

$\$ 1^{\circ} \mathrm{O}$ ensino de História do Brasil levará em conta as contribuições das diferentes culturas e etnias para a formação do povo brasileiro.

\section{Disposiçóes Transitórias}

Art. 68 - Aos remanescentes das comunidades dos quilombos que estejam ocupando suas terras é reconhecida a propriedade definitiva, devendo o Estado emitir-lhes os títulos respectivos.

Fonte: Rodrigues (2005). 
Não se tem notícia de um único caso de cumprimento de pena por condenação criminal fundada nessas leis. Já naquilo que é essencial, e que constitui uma real garantia do exercício da cidadania, o Estado brasileiro é omisso. Com efeito, o país jamais cogitou a ideia de editar medidas de cunho promocional, integrativo, suscetíveis de inserir os negros em igualdade de condiçóes no mercado de trabalho e de propiciarlhes acesso à boa educação. $\mathrm{O}$ resultado disso é o apartheid informal que todos veem, mas parecem recusar-se a enxergar (GOMES, 2001, p. 12).

Para Telles (2003), outro aspecto reducionista dessa ordem jurídica estaria no fato de a legislação antirracista restringir-se às modalidades mais ostensivas de racismo, uma vez que estas representariam apenas uma pequena parcela das várias formas de discriminação racial presentes no país. Outrossim, essa interpretação só responsabilizariaos autores criminais, desprezando que, na realidade brasileira, a discriminação é veiculada, em grande parte, por instituiçóes — mídia e sistema educacional, por exemplo — , que acabam passando ao largo da legislação antirracista.

Essa forma de enfrentamento também ignora o dado de que as discriminações e os racismos são componentes essenciais na conformação da sociedade brasileira, operando menos no plano individual do que nos planos institucional e estrutural. Um exemplo histórico desse processo é apresentado no estudo de Andrews (1998), em que estabelece um vínculo entre o racismo institucional e a política estatal no estado de São Paulo entre os anos de 1930 e 1940. Particularmente, o autor apresenta evidências da relação entre o Governo Estadual e os proprietários de terras, relação que visava ao fomentodo desenvolvimento econômico subsidiando a imigração europeia e impedindo a diversificação profissional entre os afro-brasileiros recém-libertos (ANDREWS, 1998, p. 50).

Para Andrews (1998) e Hanchard (2001), a escravidão pode ser compreendida como uma das diversas variáveis explicativas a serem consideradas para determinar por que, em 1889, apenas um ano depois da abolição, os afro-brasileiros foram afastados da competição "objetiva" do mercado de trabalho em São Paulo. Segundo a avaliação desses autores, na imigração de europeus e no tratamento diferencial concedido aos novos imigrantes, em detrimento dos afro-brasileiros, encontram-se graus de dirigismo e intervenção estatal incomuns.

Pode-se afirmar, então, que a presença do Estado foi decisiva na configuração de uma sociedade livre, que se estabeleceu com a profunda marginalização de um de seus segmentos mais amplos, qual seja, a população negra. Diante disso, responsabilizar os agentes individuais é ignorar o papel do Estado e das instituiçóes sociais na configuração das relaçóes raciais. Com isso, o potencial de impacto da carta magna de 1988 sobre as desigualdades raciais seria drasticamente reduzido. 
Ainda que a principal forma de enfrentamento da discriminação racial e do racismo na Constituição se expresse em sua criminalização, sem explicitar de forma consistente as situaçóes que caracterizam o referido crime, é preciso considerar o seu avanço em relação à Lei Afonso Arinos, de 1951 - única legislação existente até entáo, que considerava as manifestaçóes de racismo como meras contravençôes penais.

Além disso, a CF/88 consagrou um leque de direitos, como a reconsideração da África na concepção da nacionalidade brasileira, a sinalização da necessidade de que o currículo escolar reflita a pluralidade racial, o reconhecimento das terras para quilombolas e a tutela constitucional dos direitos emanados nos tratados internacionais. Essas conquistas, mesmo que aquém das reivindicaçôes do movimento negro, seriam retomadas e expandidas em legislaçóes complementares.

\section{Considerações finais}

Embora a CF/88 seja reconhecida como a constituição cidadã, a cidadania preconizada não enfrenta os dilemas históricos da questão racial no Brasil; apenas os tangencia. No entanto, a ação do movimento negro durante a ANC foi importante para que novas estratégias de atuação fossem adotadas e direitos fossem garantidos para a população negra no texto constitucional.

Além da estratégia de atuação direta na ANC, o movimento negro continuou agindo politicamente em momentos posteriores, como na definição de legislaçóes complementares à $\mathrm{CF} / 88$. Por isso, por mais ambíguo e incompleto que seja garantir, na CF, artigos que tratassem dos direitos da população negra e dos povos quilombolas, bem como afirmassem o racismo como crime inafiançável, pode ser considerado como um avanço, se comparado com outros textos constitucionais.

O imaginário social e político brasileiro é fortemente marcado pela ideia de que o Estado é capaz de projetar a sociedade. Esta é uma marca fixada em nossa intelectualidade por autores como Raymundo Faoro (1958), mas, a rigor, a nossa história mostra que o Estado apenas reflete tensôes e conflitos da própria sociedade. $\mathrm{O}$ trato dado à questáo racial pode ser considerado um exemplo: o fato de termos normas jurídicas, como a criminalização do racismo, náo garante, por si só, a sua implementaçáo. Embora do ponto de vista constitucional esse crime esteja previsto, essa garantia não é suficiente para projetar uma sociedade náo racista, na qual os racistas sejam responsabilizados criminalmente. O crime de racismo ser geralmente interpretado como injúria racial expressa não somente a ausência de elementos comprobatórios, como é alegado, mas também a ideia de harmonia racial, de ausência de conflito racial, apregoada pelo mito da democracia racial. 
Nesse caso, quem atua como arauto, denunciando o racismo para a sociedade, cobrando do Estado e da Justiça uma atuação firme e coerente com as garantias constitucionais e dando orientação às vítimas, é o movimento negro. Este movimento, na condição de movimento social, é mais importante do que a própria regulamentação das leis.

A atuação do movimento negro não pode, entretanto, ser compreendida no modelo estrito de análise dos movimentos sociais clássicos, como aqueles ligados ao mundo do trabalho. Para compreender esse movimento social é fundamental reconhecer como ele é capaz de mobilizar identidades, ancestralidades e saberes. O movimento negro atua como um educador que educa o Estado, a sociedade, a educação e reeduca a si mesmo no trato da questão racial. Seu protagonismo tem sido, portanto, decisivo para o avanço do debate sobre a questão étnico-racial no Brasil (GOMES, 2017).

A despeito das limitaçóes da $\mathrm{CF} / 88$ no que concerne à garantia da radicalidade política no tratamento da questâo racial, reivindicada pelo movimento negro ao longo da história social, política e educacional brasileira e, em especial, durante a ANC, é importante reconhecer, no marco dos seus 30 anos, que, enquanto constituição cidadã, o que se conseguiu garantir de avanço na luta antirracista no seu texto teve desdobramentos relevantes na luta por igualdade racial e por açóes afirmativas.

Reconhecemos que, mesmo com suas limitaçóes, as garantias de participação cidadã inscritas na $\mathrm{CF} / 88$ ainda são significativas na construção de projetos alternativos para o enfrentamento dos nossos dilemas e das desigualdades raciais.

A alteraçáo da LDB, Lei no 9.394/96, pela Lei no 10.639/03, tornando obrigatório o ensino de história e cultura afro-brasileira e africana na Educação Básica; o Decreto no 4.887/03, que regulamenta o procedimento para identificação, reconhecimento, delimitação, demarcação e titulação das terras ocupadas por remanescentes das comunidades dos quilombos, de que trata o art. 68 do Ato das Disposiçóes Constitucionais Transitórias (ADCT); a Lei no 12.288 , que institui o Estatuto da Igualdade Racial; a lei de cotas sociorraciais nas Instituiçóes Federais de Ensino Superior pela Lei $\mathrm{n}^{\circ} 12.711 / 12$; alei de cotas raciais nos concursos públicos pela Lei no 12.990/14; a Resolução Conselho Nacional de Educação/ Câmara de Educação Básica (CNE/CEB) no 08/2012 e o Parecer CNE/CEB no 16/2012, que instituem as Diretrizes Curriculares Nacionais para a Educação Escolar Quilombola; a criação da Secretaria de Políticas de Promoção da Igualdade Racial (SEPPIR), em 2003, pelo Governo Federal, e todos os desdobramentos das políticas de igualdade racial nos estados, nos municípios e no Distrito Federal, têm respaldo legal na $\mathrm{CF} / 88$. É certo que todos eles são resultados das pressōes e reivindicaçóes do movimento negro nas suas diversas formas de organização e expressão, mas, do ponto de vista legal, como dever do Estado e responsabilidade 
cidadã da sociedade civil, tais avanços não seriam possíveis se não tivéssemos garantido alguns direitos da população negra no texto da $\mathrm{CF} / 88$.

Lamentavelmente, a partir de maio de 2016, o país tem passado por um processo de tremendos retrocessos na política e na garantia de direitos constitucionais. Assistimos a um Poder Executivo e a um Congresso Nacional tomados por grupos de poderes conservadores, capitalistas, ruralistas, fundamentalistas que, em um pacto corrupto, impuseram, por meio de um golpe parlamentar, o impeachment da presidenta democraticamente eleita.

Esse novo perfil do Executivo, aliado aos grupos de direita e aos conservadores do Congresso Nacional, tem desencadeado uma série de alterações no texto constitucional por meio de emendas capazes de descaracterizá-lo. Porém, mais do que alterar a letra da lei, o momento atual expressa retrocessos na garantia de direitos sociais, políticos, econômicos e humanos arduamente conquistados pela sociedade brasileira antes, durante e após a promulgação da $\mathrm{CF} / 88$. "Rasgar" o texto da constituição cidadá é, nesse sentido, uma estratégia dos grupos dominantes.

Mesmo que tais retrocessos constitucionais na garantia de direitos não incidam diretamente nos artigos que marcam os direitos da populaçáo negra brasileira, todo e qualquer ataque à democracia e aos direitos afeta de maneira contundente os destinos ea vida desse segmento populacional, que representa $54 \%$ do povo brasileiro e se encontra em situação de pobreza e desigualdade.

Assim, a reforma trabalhista, a lei da terceirização, a reforma do Ensino Médio, as intençóes contidas no projeto de reforma da previdência, os ataques ao direito à terra e ao território impactam, de modo direto, negras e negros e reforçam o racismo.

Somado a isso, a extinção de importantes ministérios, como o de $\mathrm{Mu}-$ lheres, Igualdade Racial, Juventude e Direitos Humanos, o do Desenvolvimento Agrário, o do Desenvolvimento Social, além do enfraquecimento do Instituto Nacional de Colonização e Reforma Agrária (INCRA) e a recriação do Ministério dos Direitos Humanos - com poder e recursos esvaziados pelo Executivo Federal que assumiu o governo após o impeachment - significa outro golpe sobre os direitos conquistados pela populaçáo brasileira, em geral, e pela negra, particularmente. Esses ministérios e órgãos federais extintos ou esvaziados eram os que possibilitavam a implementação de políticas de direitos constitucionalmente garantidos na $\mathrm{CF} / 88$ e representavam o compromisso do Estado no atendimento às demandas históricas dos movimentos sociais, especialmente do movimento negro.

Por isso, os tempos de hoje são de luta e resistência para a retomada democrática, para que náo percamos ainda mais os avanços constitucionais da $\mathrm{CF} / 88$. Um processo que nada tem de burocrático. É político. 


\section{Notas}

1. O jornalista, advogado e militante do movimento negro, Carlos Alberto Caó, foi autor da Lei no 7.346/1985, que mudou o texto da Lei Afonso Arinos, de 1951, a qual tornava contravenção penal o preconceito de raça. Como homenagem, o texto ficou conhecido como Lei Caó. O ex-deputado constituinte faleceu em 4 de fevereiro de 2018.

2. A entrevista foi concedida no ano de 2004, durante o processo de elaboração da dissertação de mestrado (CAÓ, 2004).

3. Cabe destacar que a então senadora Benedita da Silva é uma das poucas mulheres negras na política com continuidade na carreira e atuação parlamentar. Em 2018, atua como deputada federal. Assim como ela, o entấo deputado Paulo Paim continua na sua trajetória parlamentar. Em 2018, atua como senador da República. Há outros parlamentares negros, na atualidade, no Congresso Nacional. Contudo, náo possuem renome nacional e atuam esporadicamente com a questáo racial como pauta legislativa principal.

4. Anteprojeto e Relatório da Subcomissão dos Negros, Populaçôes Indígenas, Pessoas Deficientes e Minorias, v. 196, p. 5.

5. Emenda 7, codificada como C0060-3. Diários da Constituinte.

6. Anteprojeto e Relatório da Subcomissão dos Negros, Populações Indígenas, Pessoas Deficientes e Minorias, v. 196, p. 11.

7. No anteprojeto, a questáo racial foi tratada como capítulo específico, "Dos Negros", que foi diluído já na Comissão Temática da Ordem Social.

8. Emenda 7, codificada como C0013-1. Diários da Constituinte.

9. Em entrevista no ano de 2004, durante o processo de elaboração da dissertação de mestrado (CAÓ, 2004).

\section{Referências}

ANDREWS, G.R. Negros e brancos em São Paulo (1888-1988). São Paulo: EDUSC, 1998. BRASIL. Assembleia Nacional Constituinte. VII Comissão da ordem social: anteprojeto da comissão. Brasília: Centro gráfico do Senado Federal, 1987.

BRASIL. Constituição da República Federativa do Brasil. Promulgada em 05 de outubro de 1988. Brasília: Senado Federal, 1988.

CAÓ, C.A. Carlos Alberto Caó: entrevista [2004]. Rio de Janeiro, 2004. Entrevista concedida a Tatiane Rodrigues Cosentino.

DÁVILA, J. Diploma de brancura: política social e racial no Brasil (1917-1945). Tradução de Claudia Sant'Ana Martins. São Paulo: Editora Unesp, 2006.

FAORO, R. Os donos do poder. Porto Alegre: Editor Globo, 1958. 
GOMES, J.B. Ação afirmativa e princípio constitucional da igualdade: o direito como princípio de transformação social. A experiência dos EUA. Rio de Janeiro: Renovar, 2001. GOMES, N.L. O movimento negro educador. Petrópolis: Vozes, 2017.

HANCHARD, M.G. Orfeu e o poder:o movimento negro no Rio de Janeiro e São Paulo (1945-4988). Tradução de Vera Ribeiro. Rio de Janeiro: Editora da UERJ, 2001.

RODRIGUES, T.C. Movimento negro no cenário brasileiro: embates e contribuiçóes à política educacional nas décadas de 1980-1990. 114f. Dissertação (Mestrado em Ciências Humanas) - Universidade Federal de São Carlos, São Carlos, 2005.

SANTOS, B.S. Por uma sociologia das ausências e uma sociologia das emergências. In: . (Org.). Conhecimento prudente para uma vida decente. São Paulo: Cortez, 2004. p. 777-821.

STEPAN, N.L. A hora da eugenia: raça, gênero e nação na América Latina. Rio de Janeiro: Fiocruz, 2005. (Coleção História e Saúde).

TELLES, E. Racismo à brasileira:uma perspectiva sociológica. Rio de Janeiro: Relume \& Dumará, 2003.

Recebido em 21 de maio de 2018.

Aceito em 20 de agosto de 2018. 